\title{
Integration of decision support systems to improve decision support performance
}

\author{
Shaofeng Liu*, Alex H.B. Duffy, Robert lan Whitfield and lain M. Boyle \\ Computer Aided Design Centre \\ Department of Design Manufacture and Engineering Management \\ University of Strathclyde \\ Glasgow, UK, G1 1XJ \\ *Corresponding author: liushaofeng@sina.com \\ Emails for other co-authors: \\ A.H.B.Duffy alex.duffy@strath.ac.uk \\ R.I. Whitfield ian.whitfield@strath.ac.uk \\ I.M. Boyle iain.m.boyle@strath.ac.uk
}

Received: Sep 10, 2007, Revised: Dec 05, 2008, Accepted: Dec 28, 2008

\begin{abstract}
Decision support system (DSS) is a well-established research and development area. Traditional isolated, standalone DSS has been recently facing new challenges. In order to improve the performance of DSS to meet the challenges, research has been actively carried out to develop integrated decision support systems (IDSS).

This paper reviews the current research efforts with regard to the development of IDSS. The focus of the paper is on the integration aspect for IDSS through multiple perspectives, and the technologies that support this integration. More than one hundred papers and software systems are discussed. Current research efforts and the development status of IDSS are explained, compared and classified. In addition, future trends and challenges in integration are outlined. The paper concludes that by addressing integration, better support will be provided to decision makers, with the expectation of both better decisions and improved decision-making processes.
\end{abstract}

\section{Keywords}

Literature review, integrated decision support, multiple-perspective integration, IDSS classification.

\section{Introduction}

A decision support system (DSS) is defined as an interactive computer-based information system that is designed to support solutions on decision problems (Lee and Huh 2006; Bhatt and Zaveri 2002; Shim et al 2002; Zeleznikow and Nolan 2001). The origin of DSS can be traced back to preceding work in two main research streams: theoretical study of organisational decision making undertaken by Simon et al at the Carnegie Institute of Technology during late 1950s and early 1960s, and technical work on interactive computer systems carried out by Gerrity et al at the MIT in 1960s (Keen and Scott Morton 1978). Simon's model of decision-making process consisted 
of three phases: intelligence, design and choice (Simon 1960; Simon 1977). In the model, intelligence is concerned with the search for problems, design involves the development of alternatives, and choice is about analysing the alternatives and selecting one for implementation. This classic problem-solving model of "intelligence-design-choice" has been widely accepted and adopted. Even though Simon later extended the model with a fourth monitoring phase (Simon 1997), DSS research remained primarily focussed on the original three-phase model. Work from MIT researchers including Gerrity, Keen and Scott Morton were also widely acknowledged. Gerrity's influential publication (1971) focusing on the DSS design issues. Keen and Scott Morton's work provided a broader behavioural orientation to DSS analysis, design, implementation, evaluation and development (Keen and Scott Morton 1978). Nevertheless, the study of decision making and DSS has been, and still is, undertaken in various ways and by various scholars and practitioners working in the area (Eisenhardt and Zbaracki 1992; Harrison and Phillips 1991; Nutt 2007), as well as researchers from other disciplines such as Artificial Intelligence, Operations Research, Organisational Studies and Management Information Systems that have added richness and complexity to DSS research (Hess et al 2000).

DSS research and its applications evolved significantly over the 1970s and 1980s, and DSS was considered as one of the most popular areas in information systems during the time period. Diverse DSS were developed to support decision makers at all levels in an organisation including systems that could support problem structuring, operations, financial management and strategic decision making, even extending to support for optimisation and simulation. Phenomenally, group decision support systems (GDSS) and executive information systems (EIS, now called enterprise information systems) were both developed as complementary to but more powerful support tools than DSS. GDSS can provide brain-storming, idea evaluation and communication facilities to support team problem solving (DeSanctis and Gallupe 1987; Anson et al 1995; Costa et al 2003; Limayem et al 2006). EIS extended the scope of DSS from personal or small group use to the corporate level. EIS can provide a wide variety of information such as critical success metrics, key information indicators, reports with the ability to drilldown to underlying detail, budget information, plans and objectives, competitive information, news and more (Elam and Leidner 1995; Kosaka 1994; Power 2003). However, a closer look revealed that the interest in traditional problem solving DSS appeared to be declining in the 1990s (Claver et al 2000) because of many new challenges arising for the isolated, standalone DSS.

The main challenges included: (1) technology shifts from database to data warehouse and OLAP (On-Line Analysis Processing), from mainframe to client/server architecture, and from single user model to World Wide Web access; (2) growing interconnection with more dynamic business environment and intelligence that has been addressed by many other information systems such as ERP (enterprise resource planning), SCM (supply chain management) and CRM (customer relationship management); (3) increasing complexity of the decision situations which puts enormous cognitive workload on decision makers where a user needs to have considerable knowledge and must exercise initiative to perform decision-related 
tasks. One common key issue behind the above challenges is that the traditional problem-solving characterisation of DSS has to be expanded and integrated to be compatible with new technologies, business environments and intelligence, to allow more transparent interaction between decision makers and systems, not only for improvement of the efficiency and effectiveness of the decisions, but also for collaborative support and virtual team working. While criticism of "stand-alone" DSS and the need for closely linking DSS with business intelligence and modern technologies has been voiced, many researchers have already embarked on the journey of integrated approaches aiming at addressing these requirements (Carlsson and Turban 2002). They have since introduced new concepts, frameworks and architectures for integrated DSS (Costa and Young 2003).

However, to the authors' best knowledge no publication exists that reviews the work done to address the provision of integrated decision support, even though several reviews on decision support in general have been available (Shim et al 2002; Carlsson and Turban 2002; Bohanec 2001; Eom 1999; Keen 1987). Some previous papers have addressed issues, tools, and techniques in decision support. Others have addressed integration from single viewpoint such as information integration. But none addresses the integration for decision support from multiple views, and recent development on integrated decision support systems. This paper makes the first attempt to address the integration for decision support systems from multiple perspectives including data and information integration, model integration, process integration, service integration and presentation integration. The paper reviews the state-of-the-art integration technologies and methodologies for Integrated Decision Support Systems, i.e. IDSS (rather than stand-alone DSS), so that such systems can provide improved support for decision makers to make more rational decisions. The aim of this paper is to highlight the characteristics of IDSS and discuss the challenges in design, development and implementation of such systems. In the meantime, it identifies the gaps in current research that must be addressed and provides insights into future IDSS research. The paper is organised as follows: Section 2 characterises five integration aspects that present the prospect of improvement for decision support, against which current integration approaches will be examined. Section 3 classifies and examines existing work on the IDSS from the implementation technology viewpoint. Section 4 suggests possible future research directions. Conclusions are drawn in Section 5.

\section{Multiple perspectives of integration}

As the decision making environment has become more complex and decentralised, support provided to decision makers by traditional one function or single user focused DSS has evolved from simple predefined reports to complex and intelligent agent-based analysis, suggestion and judgement (Hess et al 2000). This is because modern IDSS have been expanded and upgraded through integration of new technologies, processes and business environments into decision support paradigm to enable improved performance. This section discusses the integration for IDSS from multiple perspectives and at different levels. 
Integration may be one of the most often used words, yet most poorly defined notion (Grady 1994; Ding et al 2008). However, it is widely accepted that integration is a property of component (in the form of models, services, tools, methods, subsystems, systems etc.) interrelations. It is not a property of a single element, but of its relationships with others in the environment. Therefore, we believe that the key notion is the relationships and the properties of these relationships (Whitfield, et al 2005). In the context of IDSS, integration can be interpreted as the extent to which components of an IDSS agree. The subjects of these agreements may include data format, sharing functions, user interface conventions, and other aspects of IDSS construction.

It has been traditionally accepted that a DSS consists of three basic capability components: a data management component, a model management component and a dialogue management component (Shim et al 2002). These three elements were often represented as a DBMS (Database Management System) to manage the data, a MBMS (Model Base Management System) that manages the models to formulate the problems and solutions, and an interface that enables interactive queries, reporting, and graphing functions of decision solutions. Over the years the traditional (three-element focused) DSS have evolved into modern IDSS which not only have enriched the content of the three basic components, but also have taken into account of decision making environments and new technologies that are implemented. Figure 1 illustrates a framework of an IDSS to help identify its integration perspectives.

(1) Traditional data retrieval concept has been expanded to include the retrieval of data, information and knowledge based on data warehouses which allow multiple sources, hence the issue of data and information integration across multiple sources is crucial to IDSS;

(2) The model element in an IDSS has been expanded from traditional quantitative analysis models to include business models (such as ERP, SCM and CRM). The model integration for IDSS should consider qualitative models as well as problem solving models using quantitative analysis (Truck and Akdag 2006);

(3) New functions have been added to provide decision suggestions and judgement with the help from OLAP and data mining, artificial intelligence and expert systems. This raises the issue of service integration to allow function and service combination and sharing;

(4) The IDSS as a whole should present decision makers as end users with reduced cognitive workload to promote active interactions with the systems, which can only be achieved if presentation integration is well accomplished;

(5) Decision making process can achieve better performance if only the process units can inter-operate with each other as desired and support each other, particularly the consistency of the constraints, conditions and goals of the process units can be maintained. This raises the issue of process integration. 


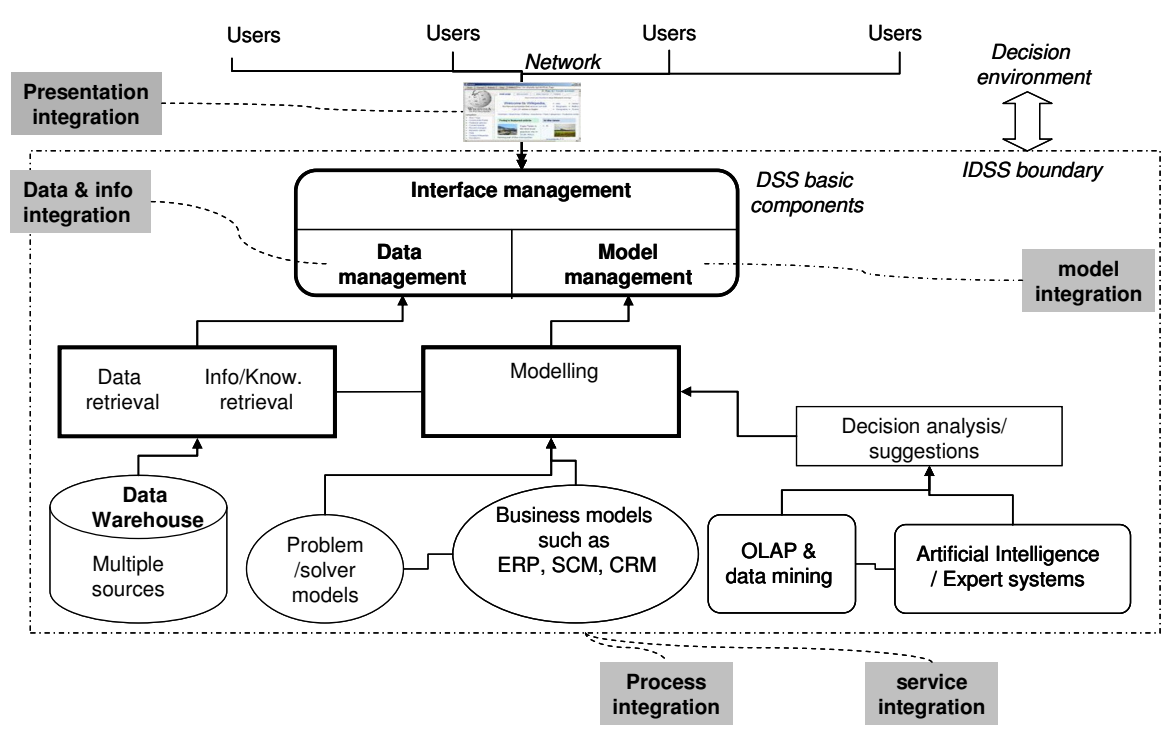

Figure $1 \quad$ Multi-perspective of integration in an IDSS framework

\subsection{Data and information integration}

The goal of data and information integration is to obtain consistent information for consistent decisions regardless of how data and information is operated on and transformed by components in a DSS. Firstly, data and information integration should reflect the use of "same" data and information by system components even though the data and information is represented differently or is deduced from other data and information. That is, data and information integration between two different components is not relevant if they deal with disjoint data and information. Secondly, data and information integration in IDSS needs to address the use of data and information from different sources.

Several properties of data and information integration have been identified in literature (Liu et al 2008; Giachetti 2004; Szykman et al 2001). These are data and information exchange, data and information consistency, non-redundancy, interoperability, and synchronisation. Table 1 summarises the main characteristics of each property.

Table 1 Characterisation of data and information integration

\begin{tabular}{|l|l|l|l|}
\hline $\begin{array}{l}\text { Integration } \\
\text { properties }\end{array}$ & Issue & Solutions \\
\hline $\begin{array}{l}\text { Data/info. } \\
\text { exchange }\end{array}$ & $\begin{array}{l}\text { Data/info. may be in } \\
\text { different form } \\
\text { communicated } \\
\text { between components }\end{array}$ & $\begin{array}{l}\text { Agree on } \\
\text { data/info. format } \\
\text { and semantics }\end{array}$ & $\begin{array}{l}\text { Little work is required for } \\
\text { components to be able to exchange } \\
\text { data/info. }\end{array}$ \\
\hline $\begin{array}{l}\text { Data/info. } \\
\text { consistency }\end{array}$ & $\begin{array}{l}\text { How well do } \\
\text { component co-operate } \\
\text { to maintain the } \\
\text { semantic constraints on } \\
\text { the data/info. they } \\
\text { manipulate }\end{array}$ & $\begin{array}{l}\text { Maintain some } \\
\text { general semantic } \\
\text { constraints on the } \\
\text { data/info. }\end{array}$ & $\begin{array}{l}\text { If each component indicates its } \\
\text { actions and effects on its data/info. } \\
\text { that are the subject of semantic } \\
\text { constraints that also refer to } \\
\text { data/info. managed by other } \\
\text { components }\end{array}$ \\
\hline
\end{tabular}




\begin{tabular}{|l|l|l|l|}
\hline $\begin{array}{l}\text { Non- } \\
\text { redundancy }\end{array}$ & $\begin{array}{l}\text { Data/info managed by } \\
\text { one component can be } \\
\text { duplicated or derived } \\
\text { from others }\end{array}$ & $\begin{array}{l}\text { Strategies for } \\
\text { timing the updates } \\
\text { to the duplicated } \\
\text { and derived } \\
\text { data/info }\end{array}$ & $\begin{array}{l}\text { Components have little duplicate } \\
\text { data/info or data/info that can be } \\
\text { automatically derived from other } \\
\text { data/info }\end{array}$ \\
\hline $\begin{array}{l}\text { Inter- } \\
\text { operability }\end{array}$ & $\begin{array}{l}\text { A system component } \\
\text { has certain views of } \\
\text { data/info }\end{array}$ & $\begin{array}{l}\text { Common view of } \\
\text { data/info by using } \\
\text { common internal } \\
\text { structures and } \\
\text { schemas }\end{array}$ & $\begin{array}{l}\text { Little work is required for } \\
\text { components to be able to use each } \\
\text { other's data/info }\end{array}$ \\
\hline $\begin{array}{l}\text { Synchroni- } \\
\text { sation }\end{array}$ & $\begin{array}{l}\text { Changes in one } \\
\text { component may affect } \\
\text { other components }\end{array}$ & $\begin{array}{l}\text { Informing each } \\
\text { other of changes } \\
\text { they make to the } \\
\text { data/info }\end{array}$ & $\begin{array}{l}\text { All the changes to all shared non- } \\
\text { persistent data/info made by one } \\
\text { component are communicated to } \\
\text { others }\end{array}$ \\
\hline
\end{tabular}

Data and information integration for DSS has been widely researched and reported. A decision support methodology for information integration is developed for Agricultural Engineering SMEs (Blackwell 2003). A good point was made that most published literature usually informs what have been done in terms of information integration, but fails to state why they have been done (Bradford and Roberts 2001; Markus and Tanis 1999). Davenport (1998) argues that information integration in companies should consider how it might strengthen or weaken competitive advantages, how it will affect company's culture and how information management will be implemented. Implementation of optimisation-based IDSS that integrate data from several sources is discussed by Cohen et al (2001). The importance of integrating knowledge management process into DSS has also been recognised so that decision makers can combine different types of knowledge (both tacit and explicit) and data (internal and external) available in various forms (Bolloju et al 2002). Zhang et al (2002) presented a knowledge management framework that integrates multiple information sources for supporting decision making in humanitarian assistance and disaster relief.

\subsection{Model integration}

The central role of models and provision of mechanisms for the management of models have been regarded as what distinguish a DSS from more traditional information processing systems (Carter et al 1992). According to (Mallach 1994) a model is a computer representation of reality that lets us investigate the impact of a possible decision. It has been proved in practice that a DSS should create multiple models rather than a single larger model for the benefit of DSS implementation, maintenance and flexibility. Model integration is the process whereby individually developed sub-models are logically combined to create a large unified model, which is important because integrated models are often needed to support rational decision making (Tsai 1998; Dolk and Kottemann 1993). An earlier review on decision models was conducted by Blanning (1993), which established the foundation for model integration. In (Tsai, 1998), the author extended structured modelling concepts and defined schema operations for formalising model integration. Two operations were defined and implemented: projection and join. Projection operation extracts a desired sub-model from a larger model for use in other applications. Join 
operation merges two models that have certain compatibility. Multi-model integration for DSS has been applied in many scenarios such as environmental management (Lam et al 2007), product development ( $\mathrm{Ni}$ et al 2006), marketing (Marquez ands Blanchar 2006), and healthcare (Nelson and Danis 2001). While many integration frameworks have been proposed for the reuse of models with different data sets for different problems (Bolloju et al 2002; Dolk 2000; Muhanna 1994), fewer studies have focused on the flexible decision making support through reuse of solvers, i.e. problem solving algorithms against diverse models and data sets (Lee and Huh 2006; Beynon et al 2002). It has been observed that integration of modelbased results into an IDSS is especially of beneficial. Prominence effects, overconfidence and other biases are reduced for managers who use model-based IDSS compared with managers who don't.

\subsection{Process integration}

Thomas and Nejmeh (1992) defined three dimensions for understanding process integration: process unit, process event and process constraint. A process unit is a unit of work that yields a result. A process event is a condition that arises during a process step that may result in the execution of an associated action. A process constraint imposes constraints on some aspects of the process.

Two components inside an IDSS are considered well integrated with respect to process if their assumptions about the process are consistent. In terms of process step integration, the goals that they achieve are part of a coherent decomposition of the process step, and if accomplishing these goals lets other components achieve their goals. With respect to event integration, components can generate and handle event notifications consistently (when one component indicates an event has occurred, another component responds to that event). Components are well integrated with respect to constraint integration if they make similar assumptions about the range of the constraints they recognise and respect.

Literature concerning process integration for IDSS applications is mainly in engineering design and manufacture area (Zdrahal and Domingue 1997; Liu and Young 2004; Saridakis et al 2005). (Liu and Young 2004) discussed consistent event notification through a knowledge model so that the processes of customer order processing, product design, and manufacturing can be seamlessly integrated in a global manufacturing environment. Earlier on, a Webcadet system presented by Rodgers et al (1999) can allow designers to use consistent design criteria and constraints for decision analysis throughout all design stages, from conceptual to detailed design. The shortcoming of this approach is that it does not tackle design knowledge understanding and structuring in collaborative decision-making. In manufacturing systems, it has been stressed that decision support and operational processes should be properly integrated (Vahidov and Kersten 2004). In such an integrated manufacturing system, an IDSS with planning and analysis capabilities writes business decisions to knowledge bases, which are then used by CAD/CAM/CAPP systems as constraints and conditions to make design decisions, further used as instructions to support processes carried out by CNCs, robots and 
other devices in a manufacturing shop. Therefore, the business intelligence is consistently used as guidelines through all the process steps to achieve the company overall goals.

\subsection{Service integration}

Service integration is essential to support flexible function combinations in an integrated decision support environment (Li and Qiu 2006). Ideally, all the functions offered by all the components should be accessible (as appropriate) to all other components, and the components need not to know what components will be constructed to use their functions (Linthicum 2003). This can be seen from two different views: first view is service integration with respect to provision, i.e. components offer services that other components in the environment require and use. Second view is service integration with respect to use, i.e. components appropriately use the services offered by other components in the environment. As components must be able to communicate the operations to be performed in order to share functionality, and operations will require data and information, the components must also communicate data and information or their references. In this sense, service integration complements data and information integration. While data and information integration addresses data and information representation, conversion, and storage issues, service integration addresses control-transfer and service-sharing issues.

Service integration and model integration are also naturally inter-related. Models are the internal view of the system's analysis capabilities, which provide the foundations for the system's functions. When the models are associated with specific decision making situations, and exposed to external world such as to decision makers (i.e. IDSS users), they become services. The major difference between model integration and service integration is in the views of the system and the association with decision situations. Model integration focuses on the inside issue of the interoperability between multiple models, while service integration focuses on the function combination from both provider's and user's viewpoints. Model integration is normally hidden from IDSS users, but is in the heat of IDSS developer's interest.

\subsection{Presentation integration}

Presentation integration aims at reducing user's cognitive load and applies to individual components, subsystems and IDSS environment as a whole (Linthicum 2003). This can be achieved through appearance and behaviour integration, as well as interaction-paradigm integration. Appearance and behaviour integration answers the questions of how easy is it for users to interact with one component, having already learned to interact with another, by addressing the similarities of component screen appearance and interaction behaviour. Components are considered well integrated with respect to appearance and behaviour integration if a user's experience with and expectations of one can be applied to the others. Furthermore, interaction paradigm addresses to what extent different components use similar metaphors and mental models to minimise learning and usage interference. In this 
sense well-integrated IDSS should use the same metaphors and mental models. It is clear that IDSS should balance the use of one metaphor versus many metaphors. One metaphor may be awkward or ill adapted for some cases, but too many metaphors may make it difficult to transfer experience between components. For example, users will be confused if they need to use two components using two navigation metaphors around a hypertext structure. Therefore, it is highly expected a common look-and-feel user interface be provided for an IDSS in terms of presentation integration to facilitate the active interaction between IDSS users and systems (Lam et al 2007).

\subsection{An overall integration framework}

Above different aspects of integration do not occur and proceed independently but rather in a combination way, study of integration in IDSS should base on a multipleperspective approach and consider the links between different integration views. An overall integration framework is therefore proposed to organise and examine the literature on the integration topic. This framework considers facets of integration levels, integration dimensions and integration types along with integration perspectives, as shown in Figure 2.

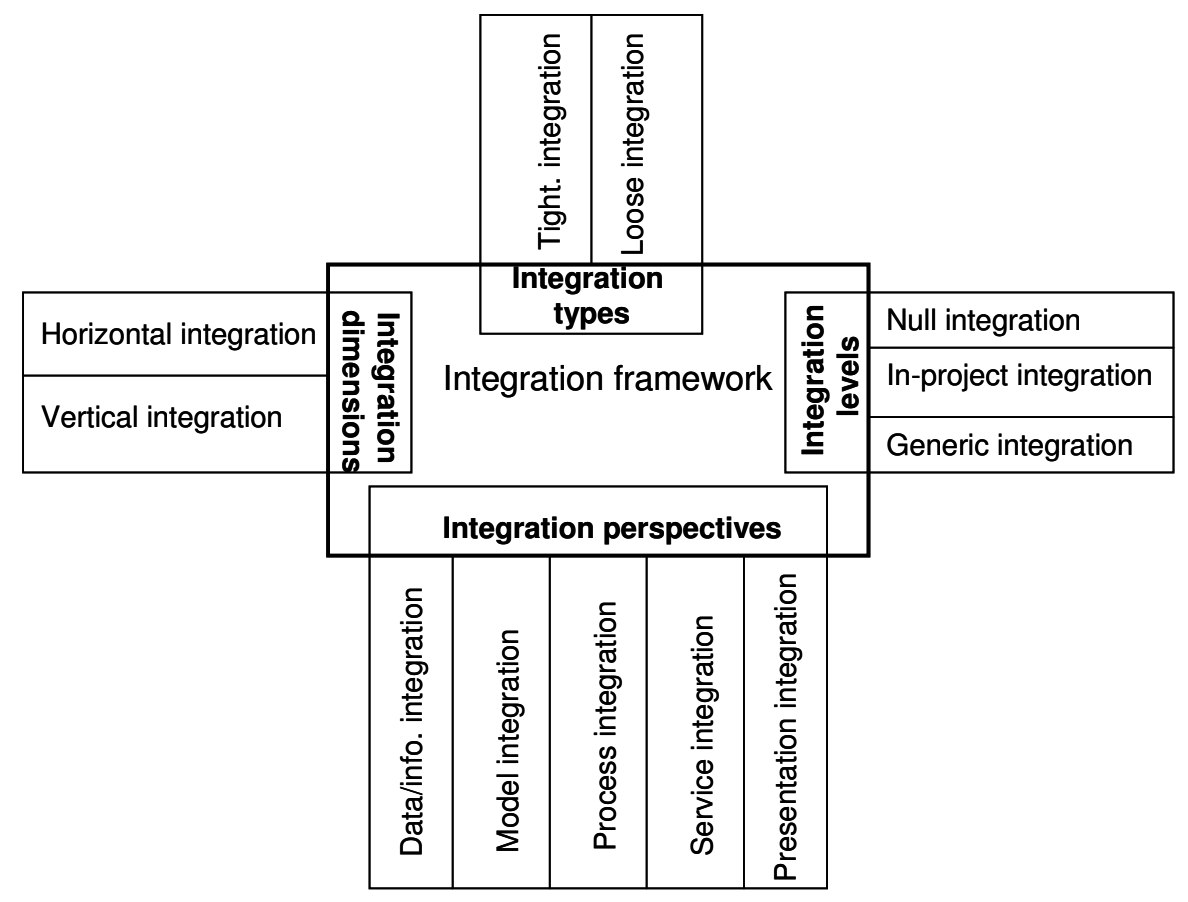

Figure 2 An integration framework

Denzer (2005) distinguished three levels of integration depths: null integration, inproject integration and generic integration. Null integration leaves end users with the problem of integrating different components by data import and export facilities only (typically files). The problem with null integration is that it results in the end users wasting incredible amount of time on importing, exporting and converting data between different systems instead of being able to spend more time on the task itself. At the same time, it produces large number of data files which none can be 
managed over long period of time. Therefore, null integration has to be improved for practical purpose. The next level, in-project integration, addresses the interconnectivity of software pieces which are often application-dependent. The process usually involves heavy programming on data exchange and user interface. The way the in-project integration is performed suits only the particular project. A different project starts with the same problems over again and will involve the same costly development process. Generic integration means generic systems composed of generic services through generic communication infrastructures, i.e. to make system's components and interfaces generic enough that reprogramming is avoided if you move from one application to another. Therefore, generic integration is the most ambitious and currently most challenging task for an IDSS (Shi et al 2007).

Integration is also often categorised into horizontal integration and vertical integration (Baker and Maropoulos 2001; Chalmeta et al 2000). Horizontal integration intends to motivate teamwork for better decision-making. Vertical integration deals with seamless linkage between upstream and downstream activities to achieve concurrent engineering. In other words, horizontal integration focuses on enabling different decision makers to work on the same task simultaneously, whereas vertical integration focuses on co-ordinating decision makers with different responsibilities to efficiently carry out interrelated tasks by managing workflow and synchronising information ( $\mathrm{Ni}$ et al 2006; Li et al 2004). However, horizontal integration and vertical integration cannot be studied separately and should be considered concurrently to achieve optimal business performance because they are complementary to each other in view of functions.

Generally, integration falls into one of the two types: tight integration and loose integration. Tight integration, also known as coupling, refers to the binding of components in such a way that they are dependent on each other, sharing the same methods, interfaces and perhaps data. In contrast, loose integration, also known as cohesion, is the "act or state of sticking together" or "the logical agreement" through a middleware (Linthicum 2004). Tight integration requires all components extensively changed to be coupled into the system. Further, as events and circumstances evolve over time, any change to any source or target system demanding a corresponding change to the integrated systems as well. On the other hand, loosely integrated components and systems are independent from each other. Therefore, loose integration offers greater flexibility. In terms of application, the convention is that if common business processes are to be reused, then a tight integration approach provides more value. Recent development in Web services clearly leverages tight integration approach.

While an overall integration framework has been discussed above, the following section will discuss how integration has been researched and addressed in different types of IDSS. To summarise, in this paper an IDSS is distinguished from a traditional DSS by:

- addressing the integration between system components from different perspectives, dimensions and at different levels of depth;

- integrating new technologies into DSS for better decision support performance; 
- integrating DSS with the decision making environment in which a DSS is situated.

The concept of IDSS was first coined in 1980s (Shi et al 2007). Since then, many IDSS have been reported which were designed for different decision problems and application domains. These systems offer varying levels of integration and interactivity. The IDSS classification in this paper considers one of the dimensions which Reich and Kapeliuk (2005) proposed for the organisation of decision problems: new technologies and methodologies that have been implemented in the IDSS.

\section{IDSS classification based on implementation technologies}

The benefits of IDSS have been clearly manifested through tangible returns to investment and cost savings in organisations over many years, it is also clear that it is new technologies that have been facilitated the integration and provided improved performance. This section reviews the IDSS that incorporated four types of state-ofthe-art technologies: knowledge-based systems, data mining, intelligent agents and Web technology. Each of these technologies provides its unique contribution to IDSS integration, as illustrated in Figure 3. Specifically, knowledge-based systems inside an IDSS work as "experts" to provide special expertise to non-expert users, and assist human experts to make consistent decisions. It enhances integration from both model and process perspectives. Data mining can discover interesting patterns hidden in huge data sets, by adopting data mining tools in an IDSS offers great support to users to interpret the decision alternatives and evaluation results, and subsequently can greatly enhance data and information integration. Incorporation of intelligent artificial in the form of agents makes an IDSS truly active and empowers the IDSS to handle dynamic environments and uncertainties. Using intelligent agents for presentation integration and process integration bears great potential to facilitate human and system interaction (IDSS integration with its environment). Finally, Internet and Web technology promotes IDSS for distribution, openness, scalability and interoperability, which is essential for service (especially Web service) integration. Even though each technology above is strong in facilitating integration in particular aspect, but in many cases the integration is facilitated across more than one perspective. 


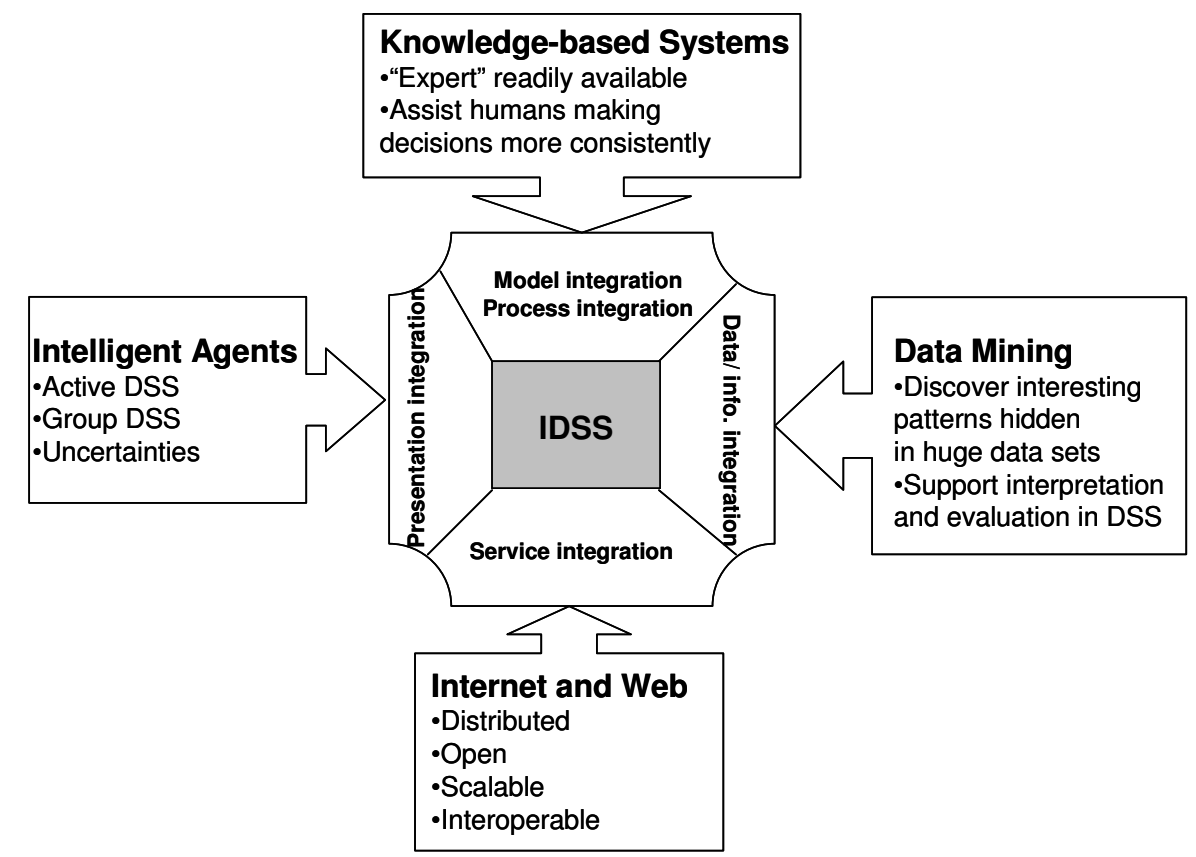

Figure $3 \quad$ Four types of technologies to enhance integration for IDSS

\subsection{Knowledge-based systems enhanced IDSS}

Knowledge-based systems (KBS), sometimes called expert systems, can perform tasks that would otherwise require human experts. The integration of KBS with DSS has improved decision making performance in two senses: (1) enhancing the quality of services by having an "expert" readily available to users when human experts are in short supply (Guerra-Zubiaga and Young 2006); (2) assisting a human expert by making their decisions more consistently (Alvarado et al 2007). Since 1990s, KBS have been playing an important role in the new generation of DSS known as IDSS. In today's rapidly changing world, agile and flexible organisations require their employees frequently change their work focus. Therefore IDSS with domain knowledge can provide better support for decisions in general, and specifically through facilitating integration of decision models and decision processes (represented by expert advice, generating alternatives and choice of choices).

Lying in the centre of KBS are the knowledge bases. Within IDSS, they are termed as model bases where hold the models of decision conditions and solutions. For model integration to be successful, appropriate approaches and methods are essential for coherently engage decision problems and conditions, with optimum decision solutions to the right decision situations. Recent work in IDSS integrating KBS can be organised around three important approaches: rule-based reasoning, case-based reasoning, and hybrid reasoning (i.e. combination of rule-based reasoning and casebased reasoning) or integration of other reasoning methods such as Bayesian networks and genetic algorithm (Boyle et al 2006; Pal and Palmer 2000). Figure 4 shows the role of KBS approaches in facilitating model integration of an IDSS. 


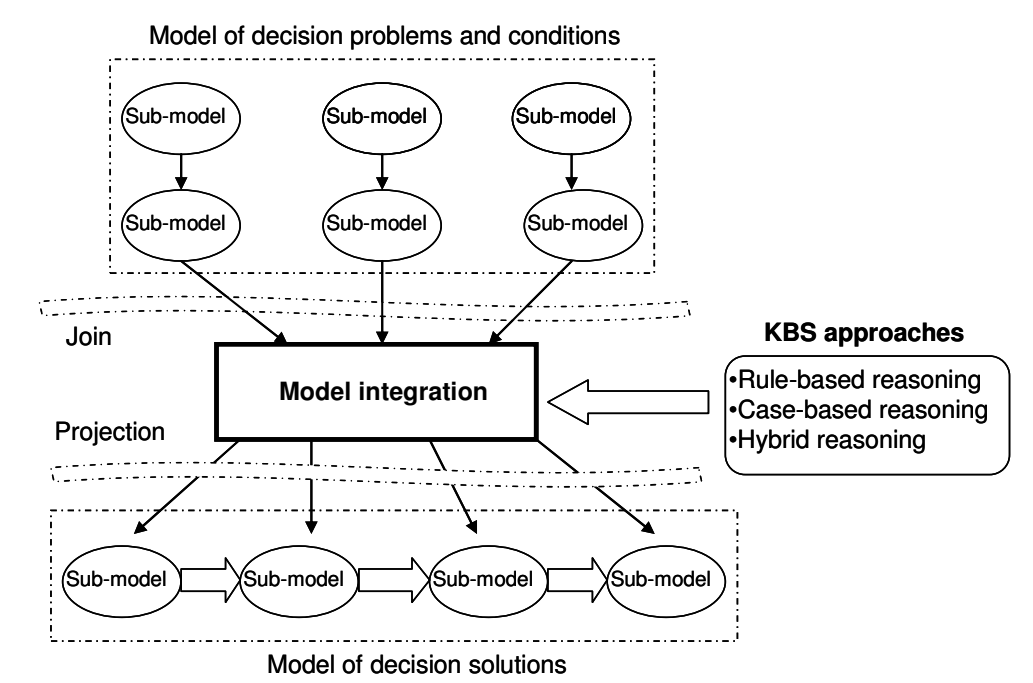

Figure $4 \quad$ KBS approaches to facilitate model integration

Taking the rule-based reasoning (RBR) approach, an integrated decision support system, named as WRPSS (Web-based Rapid Prototyping System Selector), was developed for selecting the most appropriate Rapid Prototyping process by Lan et al (2005), in which the knowledge-based system is used for determining feasible alternatives. The knowledge base holds RP (rapid prototyping) process selection models. The models are represented as production rules, which are in a form of IF, THEN, ELSE statements. A series of decision models are created according to multicriteria including technology, geometry, performance, economy and productivity. The model integration is realised by a hierarchical structure of evaluating RP process using Fuzzy Synthetic Evaluation approach, and the process integration of intelligence-design-choice (referring to Simon's decision model) is mainly investigated vertically, and the integration is considered at in-project level. It is worth noting that the WRPSS employs Browser/Server architecture and is web-based, therefore it allows developers to focus on system development and maintenance tasks on the server side in spite of the increasing number of distributed customers.

Generally, in RBR-KBS enhanced IDSS, the specialised domain knowledge is represented as a set of IF < preconditions > THEN <conclusions > rule format, and this works fine on many decision occasions, especially for well-structured decision problems. However, it is sometimes difficult to obtain a complete set of rules to cover all possible eventualities. Moreover, on ill-structured decision occasions, decision-makers often adapt old solutions to meet new demands, use old cases to explain new situations, reason from precedents to interpret a new situation. This is termed case-based reasoning (CBR) (Kolodner 1993). In recent years, CBR has been widely used in medical IDSS to support diagnosis (Lopez and Plaza 1997; Evans 1999; Frize and Walker 2002). For example, in (Huang et al 2007), CBR is integrated with data mining technology for chronic disease prognosis and diagnosis, in which CBR is used for knowledge inferring, refining and sharing. The advantage of using CBR over RBR for IDSS is clear, i.e. the CBR based IDSS can bridge at least some of the problems encountered in the RBR by representing exceptions (to the rules) in the form of cases. Therefore, integration of information and knowledge as well as models can be undertaken at a more generic level, and also because a common 
process model is normally not important for CBR based IDSS, a loose integration type often makes more sense and offers more flexibility for the system.

There is an increasing interest in combination of RBR and CBR, and integration of other reasoning methods such as Bayesian Belief Network (BBN) in developing IDSS in recent years. BBNs are probabilistic inference engines that can be used to reason under uncertainty. There is plenty of ongoing research on integrating BBNs into a wide range of decision-making fields especially to solve complex semi-structured and unstructured decision problems. For example, Lauria and Duchessi (2006) discussed how to create a BBN from real world data on information technology implementation and how it was incorporated into an IDSS to support "what-if" analysis. Anderson and Vastag (2004) explored how to use BBN for causal modelling in operations research. Kristensen and Rasmussen (2002) reported how to build a BBN for decision support in agriculture. Approaching from a slightly different angle, Lin et al (2007) discussed employing fuzzy set theory for decision making in selection data warehouse systems for enterprises, particularly on decision alternatives with decision criteria. The idea is tested through a prototype IDSS with a case study in agriculture. The system demonstrates that it is easier for decision makers to collect data, calculate data, and to interpret results (i.e. automatic ranking order of the alternatives) through utilisation of triangular fuzzy numbers, therefore the system improves the decisions by considering the vagueness, ambiguity and uncertainty prevalent in real word systems. Within above mentioned work, specific implementation of the integration solutions within specific IDSS may not be all the same, but there are three common steps in terms of model integration: search for candidate models, benchmark candidate models and apply the selected model. It is also clear that the hybrid approach greatly facilitates the model integration under dynamic and uncertain decision situations. As the reasoning methods like BBN and fuzzy theory represent models with causal relationships among a set of variables of interest, a set of conditional independence assumptions, and their related joint probabilities, and the variables-assumptions-probabilities are defined for specific applications, the integration involved in the BBN and fuzzy theory supported IDSS are often tight, in-project integration in nature.

Some recent work on KBS enhanced IDSS in terms of integration are compared and summarised in Table 2. The main integration interests addressed in the IDSS are marked with a solid black square even though some other aspects of integration may be involved (minor interests are marked with a hollow square). From the Table it can be seen that model integration is the major interest of most KBS enhanced IDSS, even though information and data integration is also required to support efficient model integration. A second commonality is that most integration is still on the inproject level with generic integration as desirable further investigation. There is no clear cross-link between integration perspectives, integration dimensions (horizontal and vertical) and integration types (tight and loose integration) according to the observation on the existing literature. 
Table 2 Comparison of integration of KBS enhanced IDSS

\begin{tabular}{|c|c|c|c|c|c|c|c|c|c|c|c|c|}
\hline & \multicolumn{5}{|c|}{ Integration perspectives } & \multicolumn{2}{|c|}{$\begin{array}{l}\text { Integration } \\
\text { dimensions }\end{array}$} & \multicolumn{3}{|c|}{ Integration levels } & \multicolumn{2}{|c|}{$\begin{array}{c}\text { Integration } \\
\text { types }\end{array}$} \\
\hline & 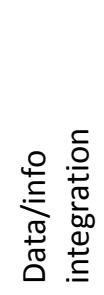 & 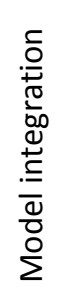 & . & 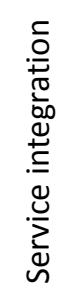 & 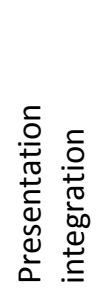 & 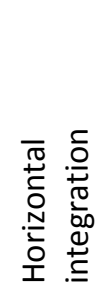 & 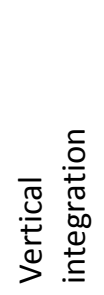 & 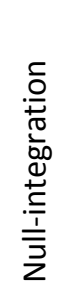 & 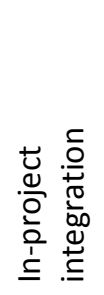 & 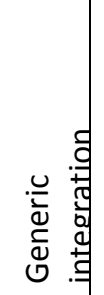 & 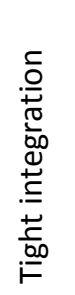 & 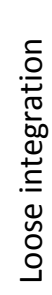 \\
\hline $\begin{array}{l}\text { Bindoff, } \\
2007\end{array}$ & $\square$ & 匹 & & & - & - & & & - & & 匹 & \\
\hline $\begin{array}{l}\text { Huang } \\
\text { et al, } \\
2007\end{array}$ & $\square$ & ! & - & & & - & - & & & - & & - \\
\hline $\begin{array}{l}\text { Kwon et } \\
\text { al, } 2007\end{array}$ & & - & - & & & & - & & - & & - & \\
\hline $\begin{array}{l}\text { Lam et } \\
\text { al, } 2007\end{array}$ & 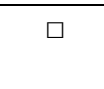 & ! & & & $\square$ & & - & & - & & & $\square$ \\
\hline $\begin{array}{l}\text { Lauria \& } \\
\text { Duchess } \\
\text { i, } 2006\end{array}$ & $\square$ & ! & & & & & - & & - & & ! & \\
\hline $\begin{array}{l}\text { Lee \& } \\
\text { Huh, } \\
2006\end{array}$ & $\square$ & ! & & & & & & & - & & ! & - \\
\hline $\begin{array}{l}\text { Lin et al, } \\
2006\end{array}$ & $\square$ & - & & & & $\pi$ & $\square$ & & - & & & $\square$ \\
\hline $\begin{array}{l}\text { Ni et al, } \\
2006\end{array}$ & $\square$ & & 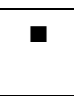 & $\square$ & & $\pi$ & ! & & - & & $\pi$ & \\
\hline $\begin{array}{l}\text { Lan et } \\
\text { al, } 2005\end{array}$ & & ! & - & & & & ! & & - & & - & \\
\hline $\begin{array}{l}\text { Liu \& } \\
\text { Young, } \\
2004\end{array}$ & $\square$ & - & & & & $\square$ & $\square$ & & - & & - & \\
\hline
\end{tabular}

\subsection{Data mining enhanced IDSS}

Independently, data mining and DSS are well-developed areas. Data mining, also known as database exploration, or information and knowledge discovery in databases, is the process of discovering new knowledge, patterns and trends from a company's databases (Eom 1999). The IDSS perception of data mining lies in that the new information, interesting patterns and trends extracted from vast amount of organisational data sources through data mining can be meaningful to obtaining valuable corporate knowledge and intelligence. The corporate knowledge and intelligence may be crucial for the decision-making process in the form of recommendations and suggestions reflecting domain expertise (Witten and Frank 1999). This can provide significant competitive advantage to an organisation (Daskalaki et al 2003; Bose and Mahapatra 2001). As part of data mining collective tools, data warehouse and OLAP have been often used in IDSS to achieve data and information integration, in the sense that data inconsistency and redundancy 
resulting from multiple sources will be eliminated during the data cleaning stage of data mining. Data warehouse was promoted as a solution for integrating data from diverse operational databases to support management of decision making (Kimball 1996). OLAP is multi-dimensional analysis which allows decision makers (analysts, managers and executives) to gain insight into data through fast, consistent, interactive access to a wide variety of possible views of information. This information has often been transformed from raw data (through integration of enterprise aggregate data across many dimensions such as product, time and location etc.) to reflect the real dimensionality of the enterprise as understood by the users (Thomsen 1997). In this paper, the term of data mining tools could comprise data warehouse, OLAP and data mining itself.

Since 1990s data mining tools have been explored for IDSS. However, the current state of using data mining for IDSS is still in its infancy. A handful of publications have been collected in the area of IDSS enhanced with data mining. These IDSS can be classified into two categories: general and specific application-oriented systems. Most of the data mining enhanced IDSS fall into the category of specific applicationoriented systems coupled with data warehouses and/or OLAP. For example, Mladenic et al (2003) presents a conceptual framework for integrating data mining into IDSS, plus methods and tools, and applying to business problems in a collaborative setting. Most IDSS integrated with data mining technology are found in medical problem domains such as for automated cardiac diagnosis (Kurgan et al 2001), quality assessment of haemodialysis services (Bellazzi et al 2005) and predicting survival time for kidney dialysis patients (Kusiak et al 2005). Integrating data mining technology into IDSS for dynamic manufacturing process was first explored by Lee (2000). Later on, Lee and Park (2003) designed a CSDSS (Customised Sampling DSS) employing data mining to carry out knowledge mining task for customer-centric electronic commerce. In the knowledge base, apart from domain knowledge, decision history and strategic knowledge are also stored. Creating knowledge for decision making employing data mining technology has been further elaborated by Huang et al (2007) through a study in diseases prognosis and diagnosis. One of the strengths of the above work is the systematic integration of data mining and case-based reasoning for the knowledge creation and knowledge inferring respectively to support doctors and patients make decisions in chronic disease treatment.

Comparatively, less work has been reported on general data mining enhanced IDSS. Recently, Shi et al (2007) explored and developed a generic data mining platform for integrated decision support called MSMiner. The major strength of the MSMiner is that it provided an integrated, extensible decision support system by employing data warehousing and data mining technologies, in which the integration of an entire decision making process (from data collection, through data modelling, data preprocessing and data mining to data visualisation) is emphasised. In the MSMiner, a subsystem called ETL (extraction, transformation and loading) is designed to clean and transform data from multiple source databases (to eliminate data inconsistency and redundancy) before integrating them into a data warehouse. The whole system is developed in a metadata-oriented way so that the interoperability and 
synchronisation of all data and information within the MSMiner (including data sources, data mining algorithms and results) is managed by metadata. The MSMiner has been applied to many application domains such as tax evasion, analysis of fishery information, and analysis of VIPs (very important people) for telecommunication corporations. The platform has an open interface for developing new data mining algorithms, adding new data pre-processing function and accessing new data sources. The platform has enough extensibility and flexibility, which demonstrates the features of a generic platform.

With regard to the performance improvement of data mining enhanced IDSS, the following advantages have been observed, as illustrated in Figure 5. The data mining process can be seen as a knowledge creation phase in the whole data mining enhanced decision making process, in which the data sets undergo cleaning and preprocessing for removing discrepancies and inconsistencies to improve its quality. The selected data set is then analysed to identify patterns that represent relationships among data by applying algorithms such as decision tree induction. Association rules are then mined out from the implicit relationships within the domain data. It is clear that by taking advantage of data mining technology in IDSS, the decisions can be made based on organisational knowledge rather than raw data or information. As the knowledge output from data mining process is transformed from patterns and trends with combination of acknowledgement of business goals and practical plans, it provides decision makers with purpose and requirements-oriented support rather than unfocussed information support. Data mining reveals implicit relationships behind data itself, which can assist decision makers obtaining overall perceptions of decisions in an organisation. Information flowing through an IDSS without data mining process can be disjoint with discrepancy and inconsistency, which leads to poor decision support. Therefore, the performance of IDSS can be greatly improved through data mining to provide better decision support - knowledge with quality, business relevance and understood by users from multi-dimensions.

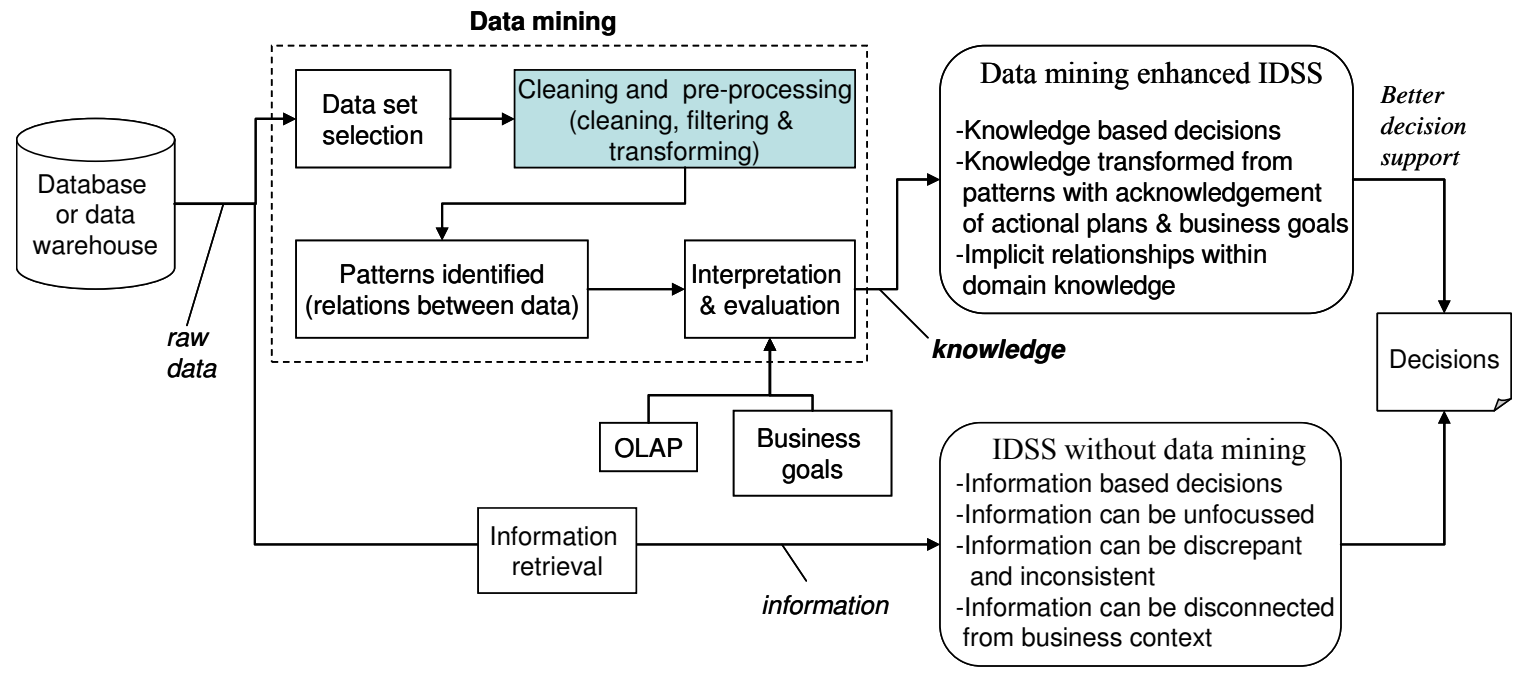

Figure $5 \quad$ Data mining enhanced IDSS for better decision support

\subsection{Intelligent agents enhanced IDSS}


The need for active decision support was first asserted by Keen when he outlined "the next decade of DSS" (Keen 1987). In late 1980s and early 1990s, researchers started to explore the possibility of utilising intelligent agents for DSS performance improvement with respect to its activeness. Intelligent agents are also known as intelligent interfaces or adaptive interfaces. Intelligent agent research has been emerging as a multidisciplinary research area involving researchers from such fields as DSS, cognitive science, psychology etc (Duffy 1997; Riecken 1994). One fundamental justification for using intelligent agents to enhance IDSS was originated from the weak performance of traditional DSS, i.e. its passiveness of interaction. It was argued that there should be more active interactions between DSS users and systems in decision-making process (Raghavan 1991; Rao et al 1994). Typical characteristics of intelligent agents include: intelligence, autonomy, pro-activeness, purposefulness, competence, reasoning capability, and interaction with environment and other agents. These features make agents attractive to and suitable for developing active, communicative and co-operative IDSS. From the interoperability and synchronisation viewpoint, intelligent agents can facilitate presentation integration, process integration and information integration.

Earlier publications were focussed on the architecture of active IDSS. Subsequently, numerous research and IDSS have been reported based on software agents (Rodgers et al 1999; Hess et al 2000; Lee and Park 2003; Vahidou and Kersten 2004; Lee and Huh 2006; Zhu et al 2006) to support wide range of decision tasks including diagnosis (Thapa et al 2005; Niu et al 2007), information representation and retrieval (Kebair and Serin 2006), electronic commerce (Lee and Park 2003) exception management (Wang et al, 2004), and data flow management (Turck et al 2007). From these developments and systems, it has been noticed that over the years the use of agents in IDSS has shifted from Keen's (1987) original advocate (exploitation of emerging software tools and artificial intelligence to built semi-expert systems) to multi-agent systems and software computing. In fact, rather than stand-alone modules, intelligent logic is now inherently incorporated in IDSS together with other modern IT technologies such as data mining and Web technology to provide higher-level and more comprehensive integration services.

The agents in IDSS were particularly suitable for performing integration/ coordination of processes as well as specific tasks/ processes to assist achieving global solutions in dynamic and unpredictable environments. In (Lee and Park 2003), three agents were implemented in the prototype IDSS: a knowledge mining agent to actively discover sampling knowledge that provides support in the available customised sampling method generation, a user assistant agent to accomplish the integration between a particular decision maker and the sampling knowledge mining agent (to achieve presentation integration), and an adaptation agent to integrate and co-ordinate functions across all the agents in the system. In (Wang et al 2004), three types of agents were designed working together to support decisions in security exception management. Integration agents worked as a bridge between the exception management and existing security transaction systems. Task agents were deployed to perform data monitoring and exception repair activities. A repository 
agent integrates different types of information such as real-time trade data for monitoring, reports for exceptions that have been deleted, exception reconciliation status. Both of the above research work addressed the integration from information, process and presentation perspectives. The information integration in both cases is achieved in the same manner through the concept of a consistent knowledge repository. The means to achieve process and presentation integration are slightly different. Wang et al (2004) directly used integration agents, but Lee and Park (2003) employed a sampling adaptation agent for co-ordination. In both ways the awareness has been achieved of other agents and their capabilities as integration among the agents occur, therefore the IDSS obtained the notification of process and task constraints for process integration. In terms of tighter integration and higher degree of direct integration with problem domains through agents, Vahidov and Kersten (2004) introduced a decision station for investment decision support which has agents working as sensors and effectors to gain business intelligence from the environment and to impose impact onto the environment. The sensor agents collect information from multiple sources including financial markets, historical information, analyst's opinions, news articles and other relevant sources, perform normal tasks as transformations and calculations, and advanced tasks, e.g. based on the market volatility they could decide to monitor market more closely (planning capability) and adjust the levels at which the alert signals are generated (adaptive capability). The effector agents can engage in variable activities required to implement a decision, for example, converting the decision into more detailed plans, optimising the wellstructured aspects of a decision, determining sequence of actions, monitoring execution of a decision, and even negotiation in the course of implementing a decision. In the meantime, data and information integration is achieved through the interoperability among the sensor agents, IDSS kernel and effector agents.

Other examples of agent enhanced IDSS include agents for group decision support (Shaw and Fox 1993), for strategic planning (Pinson et al 1997), for handling uncertainties (Ekenberg et al 1997), for business process management (Jennings et al, 2000), and for multi-criteria decision analysis (Ekenberg et al 1996; Kaklauskas et al 2007). So far intelligent agents have demonstrated tremendous potential in supporting well-defined processes/ tasks such as data conversion, information filtering and data mining (Bui and Lee 1999), and have promised support for illstructured tasks in dynamic co-operation (Orwig et al 1996).

Integrating agents into IDSS has shown that the decision support performance is improved, in the sense that IDSS is not only working as a tool that can monitor decision making process, but also can stimulate creative ideas through active interaction between IDSS users and systems. This is because agents enhanced IDSS allow users (decision makers) to have insightful conversations, aided by presentation integration, with the systems when they continuously formulate and inquiry about the decision problems under dynamic circumstances. In essence, the agents offer IDSS with the capability to help and engage decision makers in the form of teaching, learning and performing tasks. The active IDSS can work as experts, servants and mentors and know when and how to provide advice and criticisms. This cycle has been illustrated in Figure 6. 


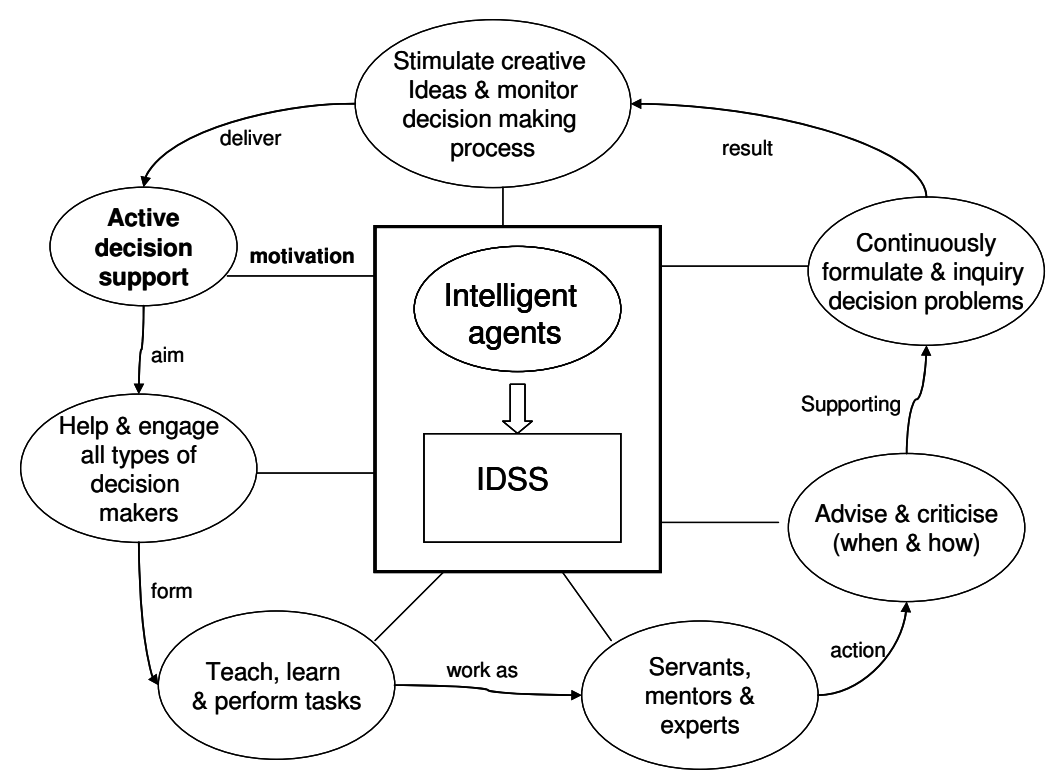

Figure 6 Agent enhanced IDSS to improve decision support performance

\subsection{Web-enhanced IDSS}

Internet and Web technology has presented a new world to IDSS in the sense that Web is not only emerging as the development and delivery platform for IDSS, but also IDSS can be more scalable and interoperable in network-based business environment (Liu et al 2006). Many stand-alone DSS lack knowledge orientation and collaborative decision making in conflict reconciliation process, which is crucial for strategic planning and group decision making. At the beginning of the $21^{\text {st }}$ century, the Web is at the centre of activity in developing IDSS. When vendors propose a Web-based IDSS, they are referring to a computerised system that delivers decision support information or decision support tools to a manager or business analyst using a Web browser such as Netscape Navigator or Internet Explorer. A major motivation for using Web technology to enhance IDSS is that IDSS environments are rapidly changing from centralised and closed to distributed and open in Internet computing.

As discussed in the Section 2 of this paper, service integration has remained a constant challenge and interest in the development of IDSS. Three types of service integration have been actively researched in supporting decision-making: interfacewrapping services, MAS (Multi-Agent System) services and Web services. While interface-wrapping services set up the foundation to develop and deploy services in the network, MAS leverage artificial intelligent technology to make them more autonomous, robust and mobile for IDSS. It is Web services however, based on XML (eXtensible Mark-up Language) schemas and a communication protocol known as SOAP (Simple Object Access Protocol), that provides the capability to be published, located and invoked across the Web to truly support collaborative decision making. At the moment, the issues presented to IDSS by Web services include interoperability, cross-platform and information security (Li and Qiu 2006). Nevertheless, Web service has been widely adopted as promising technology to support open and distributed decision making in wide decision making scenarios including security 
exception management (Wang et al 2004), mould industry (Silva et al 2006), codesign and concurrent engineering ( $L i$ et al 2004), and distributed product design evaluation (Rodgers et al 1999). In the last literature, an IDSS named as WebCADET was developed adopting the "knowledge server" paradigm. WebCADET integrates a knowledge-based system in which the inference engine and knowledge bases are located on a server computer. Its user interface is exported on demand to client computers via the Internet and Web.

It should be noted that, unlike agents, Web services are not designed to use and reconcile ontology. A Web service knows only about itself, while agents often have awareness of other agents and their capabilities as interactions among the agents occur. Agents are inherently communicative, whereas Web services are passive until they are invoked. Agents are co-operative, and by forming teams and coalitions they can provide higher level and more comprehensive services, while current standards for Web services don't provide composing functionalities (Byung 2003; Huhns 2002). Wang et al (2004) explored integrating both Web service and agent technology into IDSS with the purpose of overcoming the limitations of their own.

The publications have shown that integrating Web technology for IDSS demonstrates many benefits including: (1) global access to decision support functions and services available to managers over a proprietary intranet, to customers and suppliers over an extranet, or to any stakeholders over Internet; (2) to improve the rapid dissemination and sharing of "best practices" analysis and decision making frameworks; (3) to promote more consistent decision making on repetitive tasks (Shim et al 2002; Eom 1999).

\section{Research challenges and future research directions}

Examining the development of DSS over last three decades has guided us in understanding the evolution to IDSS. Certain challenges and trends for integration of IDSS have been observed from two different viewpoints: specific integration aspect viewpoint and general integration viewpoint.

\subsection{Challenges and possible directions for specific integration aspects}

4.1.1 Data and information integration is the most fundamental issue for all integration aspects, and is in no doubt a continuous research hot topic for all IDSS because data is the basic format for decision variables, constraints and objective functions. New data management technologies such as data warehousing, OLAP and data mining have been widely employed in IDSS to handle data and information integration from multiple sources, to provide multiple presentation and business intelligence/ knowledge to users. Research challenges include how to keep high consistency between the data, information, and knowledge when they are transformed to different formats, and how to maintain efficiency when there are huge quantities of data being processed, especially when graphical representation of data is involved. 
4.1.2 From model integration point of view, more work need to be carried out on integrating of qualitative modelling methods in IDSS. Qualitative modelling methods are becoming increasingly important for IDSS to explore symbolic qualitative aspects of the decision process: experience, intuition, judgement, and specialist expertise. Ideally, future IDSS would provide a seamless integration of qualitative methods with currently prevailing quantitative modelling, simulation and optimisation methods. As advocated by Chae et al (2005), IDSS should support integration of the quantitative aspects of moral intensity - magnitude of consequences, concentration of effect, and probability of effect- into the quantified aspects of the non-ethical formulation. Same desire has been voiced by (Paradice 2002) for consideration of ethical and by (Courtney 2001) for consideration of aesthetical issues. However, this ability will require for dynamic model modification. What have been lacking to date are some specific suggestions as how ethical concerns can be incorporated into the IDSS design process. Another challenge for model integration is the adaptability of the models (of decision problems and solutions) to organisational needs for changes as more organisations have constructed the IDSS distributed across their internal and external networks and changes occur more frequently. One suggestion was made by Lee and Huh (2006) by combination use of loosely and tightly integrated models when appropriate. The key is the "appropriateness", which will need more investigation.

4.1.3 A big challenge for process integration is the creation of a common decision making process across different organisation levels that top mangers, middle mangers and technical personnel face with coverage from structured decisions through semi-structured decisions to nonstructured decisions. Further research efforts are needed on process dependency management between process units, process assumptions and process constraints under complex decision situations.

4.1.4 Challenges for presentation integration are: firstly, how should an IDSS provide different interaction for technical users and public users taking into account user's domain knowledge, experience and behaviour, but based on consistent system data, information and models? Secondly, how to improve the performance of intelligent agents as active interactions between IDSS and their users, especially for novice users.

4.1.5 Service integration has been dominated by web service development over past decade because of the emergence of Internet and Web technology, which should be a continuous research interest over many years in the future.

\subsection{General future research suggestions}


Further research effort is required for general integration issues including:

- Generality and extensibility of the integration approaches and processes implemented in an IDSS;

- Flexibility versus reliability, i.e. the tradeoffs between loose integration and tight integration of data and models;

- Moving from null and in-project integration to generic integration to extend the utilisation of IDSS from application-dependent to applicationindependent, in particular to meet the requirements of support for unstructured and semi-structured decisions;

- From IDSS to a generic integrated decision support environment (Liu et al 2008), which can configure and re-configure readily available specific standalone DSS and decision support tools for different decision makers to solve different decision tasks under different circumstances, with high adaptability and self- adjustment capability, and with graceful degradation when specific stand-alone components within an IDSS breaks down.

\section{Conclusions}

Distinguished from traditional management information systems, a DSS is decision focussed, user initiated and controlled, and combines the use of models and analytical techniques with traditional data access and retrieval functions. While the primary purpose of a stand-alone DSS is to improve the performance of individual decision maker - to improve the quality of his or her decision making by improving its effectiveness and efficiencies, IDSS have demonstrated its advantages in providing consistent, co-ordinated, active and global support for multiple users on varied decisions in an organisation. The integration within an IDSS can be addressed not only from data, model, and presentation (user interface) perspectives, but also from service and process viewpoints. The above integration can be enhanced through the state-of-the-art technologies and methodologies such as knowledge-based systems, data mining, intelligent agents and the Web technology.

This paper has reviewed the background, the current state of the art of the IDSS, key integration issues and their positive impact on the decision support performance. Selected collection of publications have been analysed to establish the key integration perspectives that IDSS have been embraced, and to establish an initial view on how integration has improved decision support performance, not only in the sense of what support IDSS can provide, but also in the way how the decisions are made. It can be expected that the key strategies of whole decision-making process will be substantially affected along with the advances of integration technology and methodology in the future.

The research reviewed in this paper has concentrated on the technologies and methods for the integration of decision support systems. The IDSS have improved performance compared with isolated, stand-alone DSS but still with fixed functions. Future work should investigate more generic integration frameworks that allow IDSS to evolve into an integrated decision support environment (IDSE), which can flexibly configure and re-configure its functions to fast respond to varied decision 
requirements resulting from dynamic business situations. Research challenges of developing such an IDSE include two aspects: (1) the trade-off between loose and tight integration strategies within the integration frameworks to achieve the balance between the flexibility and reliability of the IDSE. (2) The seamless integration across data, models and processes within the integration frameworks so that the IDSE can provide coherent and consistent services and presentations to decision makers.

\section{Acknowledgement}

The research reported in this paper has been undertaken at the Computer Aided Design (CAD) Centre in the University of Strathclyde, United Kingdom. The work was funded by both BAE Systems and UK Engineering and Physical Science Research Council (EPSRC) under grant number EP/D505461/1 for the project "Network Enabled Capability Through Innovative Systems Engineering (NECTISE)".

\section{References}

Alvarado M, Rodriguez-Toral MA, Rosas A and Ayala S (2007) Decision making on pipe stress analysis enabled by knowledge-based systems. Knowledge and Information Systems: An International Journal 12(2): 255-278.

Anderson R and Vastag G (2004) Causal modelling alternatives in operations research: overview and application. European Journal of Operational Research 156(1): 92-109.

Anson R, Bostrom RP and Wynne BE (1995) An experiment assessing group system and facilitator effects on meeting outcomes. Management Science 41(2): 189-208.

Baker RP and Maropoulos PG (2001) An architecture for the vertical integration of tooling considerations from design to process planning. Robotics and Computer Integrated Manufacturing 16(2-3): 121-131.

Bellazzi R, Larizza C, Magni P and Bellazzi R (2005) Temporal data mining for the quality assessment of hemodialysis services. Artificial Intelligence in Medicine 34(1): 25-39.

Beynon M, Rasmequan S and Russ S (2002) A new paradigm for computer based decision support. Decision Support Systems 33: 127-142.

Bhatt GD and Zaveri J (2002) The enabling role of decision support systems in organisational learning. Decision Support Systems 32(3): 297-309.

Bindoff IK, Tenni PC, Peterson GM, Kang BH and Jackson SL (2007) Development of an intelligent decision support system for medication review. Journal of Clinical Pharmacy and Therapeutics 32: 81-88.

Blackwell P (2003) A decision-making methodology for integrating information systems within SMEs. Engineering Doctor Thesis, Cranfield University, UK.

Blanning RW (1993) Model management systems: an overview. Decision Support Systems 9: 9-18.

Bohanec M (2001) What is decision support? Proceedings of Information Society: Data Mining and Decision Support in Action! (edited by Skrjanc M and Mladenic D) Ljubljana, pp. 86-89.

Bolloju N, Khalifa M and Turban E (2002) Integrating knowledge management into enterprise environments for the next generation decision support. Decision Support Systems 33: 163-176.

Bose I and Mahapatra R (2001) Business data mining - a machine learning perspective. Information and Management 39: 211-225. 
Boyle I, Rong Y and Brown DC (2006) CAFixD: a case-based reasoning fixture design method, framework and indexed mechanisms. Journal of Computing and Information Science in Engineering 6: 40-48.

Bradford M and Roberts D (2001) Does your ERP system measure up? Strategic Finance 83(3): 30-34.

Bui T and Lee J (1999) An agent-based framework for building decision support systems. Decision Support Systems 25(3): 225-237.

Byung KQ (2003) Meta Web service: building Web-based open decision support system based on Web services. Expert Systems with Applications 24: 375-389.

Carlsson C and Turban E (2002) DSS: directions for the next decade. Decision Support Systems 33: 105-110.

Carter GM, Murray MP, Walker RG and Walker WE (1992) Building Organisational Decision Support Systems. Academic Press Inc. Boston, USA.

Chae B, Paradice D, Courtney JF and Cagle CJ (2005) Incorporating an ethical perspective into problem formulation: implications for decision support systems design. Decision Support Systems 40: 197-212.

Chalmeta R, Campos R and Grangel R (2000) Reference architecture for enterprise integration. The Journal of Systems and Software 57(1): 175-191.

Claver E, Gonzales R and Llopis J (2000) An analysis of research in information systems (1981-1997). Information and Management 37: 181-195.

Cohen M, Kelly CB and Medglia AL (2001) Decision support with Web-based software. Interface 31(2): 109-128.

Costa CA and Young RIM (2003) Interactions elements: utilizing knowledge to provide high quality information in a decision support system. Edited by JARDINGONÇALVES, Ricardo; CHA, J.; STEIGER-GARÇÃO, Adolfo. Concurrent Engineering: The Vision for the Future Generation in Research and Applications - Enhanced Interoperable Systems - Lisse - Holanda, pp 727-734.

Costa JP, Melo P, Godinho P and Dias LC (2003) The AGAP system: a GDSS for project analysis and evaluation. European Journal of Operational Research 145(2): 356-367.

Courtney JF (2001) Decision making and knowledge in inquiring organisations: a new decision making paradigm for DSS. Decision Support Systems 31: 17-38.

Daskalaki S, Kopanas I, Doudara M and Avouris N (2003) Data mining for decision support on customer insolvency in telecommunication business. European Journal of Operational Research 145: 239-255.

Davenport TH (1998) Putting the enterprise into the enterprise system. Harvard Business Review 76(4): 121-131.

Denzer R (2005) Generic integration of environmental decision support systems state of the art. Environmental Modelling \& Software 20: 1217-1223.

DeSanctis $G$ and Gallupe RB (1987) A foundation for the study of group decision support systems. Management Science 33(5): 589-609.

Ding L, Davis D and McMahon CA (2008) The integration of lightweight representation and annotation for collaborative design representation. Research in Engineering Design. DOI 10.1007/s00163-008-0052-3

Dolk DR (2000) Integrated model management in the data warehouse era. European Journal of Operational Research 122: 199-218.

Dolk DR and Kottemann JE (1993) Model integration and a theory of models. Decision Support Systems 9(1): 51-63. 
Duffy AHB (1997) The "what" and "how" of learning in design. IEEE Expert Intelligent Systems and their Applications 12(3): 71-76.

Eisenhardt K and Zbaracki M (1992) Strategic decision making. Strategic Management Journal 13:17-37.

Ekenberg L, Danielson M and Bosman M (1996) From local assessments to global rationality. International Journal of Co-operative Information Systems 5(2-3): 315331.

Ekenberg L, Danielson M and Mangus B (1997) Imposing security constraints on agent-based decision support. Decision Support Systems 20(1): 3-15.

Elam JJ and Leidner DG (1995) EIS adoption, use and impact: the executive perspective. Decision Support Systems 14(2): 89-103.

Eom SB (1999) Decision support systems research: current state and trends. Industrial Management and Data Systems 99(5): 213-220.

Evans CD (1999) A case-based assistant for diagnosis and analysis of dimorphic syndromes. Medical Information 20: 121-131.

Frize $M$ and Walker R (2002) Clinical decision support systems for intensive care units using case-based reasoning. Medical Engineering and Physics 22(9): 671-677.

Gerrity TP (1971) The design of machine decision systems: an application to portfolio management. Sloan Management Review 12(2): 59-75.

Giachetti RE (2004) A framework to review the information integration of the enterprise. International Journal of Production Research 42(6): 1147-1166.

Grady JO (1994) System Integration. CRC Press LLC, Washington D.C.

Guerra-Zubiaga DA and Young RIM (2006) A manufacturing model to enable knowledge maintenance in decision support systems. Journal of Manufacturing Systems 25: 122-136.

Harrison M and Phillips B (1991) Strategic decision making: an integrative explanation. Research in the Sociology of Organizations 9: 319-58.

Hess TJ, Rees LP and Rakes TR (2000) Using autonomous software agents to create the next generation of decision support systems. Decision Science 31(1): 1-31.

Huang MJ, Chen MY and Lee SC (2007) Integrating data mining with case based reasoning for chronic disease prognosis. Expert Systems with Applications 32: 856867.

Huhns MN (2002) Agents as Web services. IEEE Internet Computing 6(4): 93-95.

Jennings NR, Faratin P, Norman TJ, O'Brien P and Odgers B (2000) Autonomous agents for business process management. International Journal of Applied Artificial Intelligence 14(2): 145-189.

Kaklauskas A, Zavadskas EK and Trinkunas V (2007) A multiple criteria decision support online system for construction. Engineering Application of Artificial Intelligence 20(2): 163-175.

Kebair F and Serin F (2006) Multiagent approach for the representation of information in a decision support system. Lecture Notes in Computer Science 4183: 83-107.

Keen P (1987) Decision support systems: the next decade. Decision Support Systems 3(3): 253-265.

Keen P and Scott Morton M. (1978) Decision Support Systems: An Organisational Perspective. Addison-Wesley Publishing. Reading, MA.

Kimball R (1996) The Data Warehouse Toolkit. John Wiley \& Sons, New York, NY. 
Kolodner J (1993) Case-based Reasoning. Morgan Kaufmann Inc. California. Kosaka T (1994) The first investigation of executive information systems practices in Japanese firms. Proceedings of the TIMS/ORMA Conference, Boston.

Kristensen K and Rasmussen I (2002) The use of Bayesian network in the design of a decision support system for growing malting barley without use of pesticides. Computers and Electronics in Agriculture 33(3): 197-217.

Kurgan LA, Cios KJ, Tadeusiewicz R, Ogiela M and Goodenday LS. 2001. Knowledge discovery approach to automated cardiac SPECT diagnosis. Artificial Intelligence in Medicine 23(2): 149-169.

Kusiak A, Dixon B and Shah S (2005) Predicting survival time for kidney analysis patients: a data mining approach. Computers in Biology and Medicine 35(4): 311-327. Kwon O, Kim KY and Lee KC (2007) MM-DSS: Integrating multimedia and decision making knowledge in decision support systems. Expert Systems with Applications 32: 441-457.

Lam D, Leon L, Hamilton S, Crookshank N, Bonin D and Swayne D (2007) Multi-model integration in decision support system: a technical user interface approach for watershed and lake management scenarios. Environmental Modelling and Software 19: 317-324.

Lan H, Ding $Y$ and Hong J (2005) Decision support system for rapid prototyping process selection through integration of fuzzy synthetic evaluation and an expert system. International Journal of Production Research 43(1): 169-194.

Lauria EJM and Duchessi PJ (2006) A Bayesian belief network for IT implementation decision support. Decision Support Systems 42: 1573-1588.

Lee JH (2000) Artificial intelligence-based sampling planning system for dynamic manufacturing process. Expert Systems with Applications 22(2): 117-133.

Lee JH and Park SC (2003) Agent and data mining based decision support system and its adaptation to a new customer-centric electronic commerce. Expert Systems with Applications 25: 619-635.

Lee KW and Huh SY (2006) A model-solver integration framework for autonomous and intelligent model solution. Decision Support Systems 42: 926-944.

Li WD, Huh JYH and Wong YS (2004) An internet-enabled integrated system for codesign and concurrent engineering. Computers in Industry 55(1): 87-103.

Li WD and Qiu ZM (2006) State-of-the-art technologies and methodologies for collaborative product development systems, International Journal of Production Research, 44(13): 2525-2559.

Limayem M, Banerjee P and Ma L (2006) Impact of GDSS: opening the black box. Decision Support Systems 42: 945-957.

Lin HY, Hsu PY and Sheen GJ (2007) A fuzzy-based decision making procedure for data warehouse system selection. Expert Systems with Applications 32: 939-953.

Lin L, Hu PJH, Sheng ORL (2006) A decision support system for lower back pain diagnosis: uncertainty management and clinical evaluations. Decision Support Systems 42: 1152-1169.

Linthicum DS (2003) Next Generation Application Integration: from Simple Information to Web Services. Addison-Wesley, Boston.

Liu S, Duffy AHB, Whitfield RI and Boyle IM (2008) An integrated decision support environment for organizational decision making. International Conference on Collaborative Decision Making (CDM'08). In proceedings of Collaborative Decision 
Making: Perspectives and Challenges. ISSN 0922-6389. pp. 392-401. Toulouse, France, $1^{\text {st }}-4^{\text {th }}$ July.

Liu S, McMahon and Culley SJ (2008) A review of structured document retrieval technology to improve information access performance in engineering document management. Computers in Industry 59(1): 3-16.

Liu S, McMahon CA, Darlington MJ, Culley SJ and Wild PJ (2006) A computational framework for retrieval of document fragments based on decomposition schemes in engineering information management. Journal of Advanced Engineering Informatics 20(4): 401-413.

Liu S and Young RIM (2004) Utilising information and knowledge models to support global manufacturing co-ordination decisions. International Journal of Computer Integrated Manufacturing 17(6): 479-492.

Lopez B and Plaza E (1997) Case-based learning of plans and goal states in medical diagnosis. Artificial Intelligence in Medicine 9: 29-60.

Mallach EG (1994) Understanding Decision Support Systems and Expert Systems. Irwin (Burr Ridge, Illinois).

Markus ML and Tanis C (1999) The enterprise systems experience - from adoption to success. Claremont Graduate University: California.

Marquez AC and Blanchar C (2006) A decision support system for evaluating operations investments in high-technology business. Decision Support Systems 41: 472-487.

Mladenic D, Lavrac N, Bohanec M and Moyle S (2003) Data Mining and Decision Support: Integration and Collaboration. Springer.

Muhanna WA (1994) SYMMS: a model management system that supports model reuse, sharing, and integration. European Journal of Operational Research 72: 214243.

Nelson JE and Danis M (2001) End-of-life care in the intensive care unit: where are we now? Critical Care Medicine 29(2): N2-N9.

Ni QF, Lu WF, Yarlagadda PKDV and Ming XG (2006) A collaborative engine for enterprise application integration. Computers in Industry 57: 640-652.

Niu G, Han T, Yang BS and Tan ACC (2007) The multi-agent decision fusion for motor fault diagnosis. Mechanical Systems and Signal Processing 21(3): 1285-1299.

Nutt PC. 2007. Intelligence gathering for decision making. International Journal of Management Science 35: 604-622.

Orwig R, Chen H, Vogel D and Nunamaker J (1996) A multi-agent view of strategic planning using group support systems and artificial intelligence. Group Decision and Negotiation 5(1): 37-59.

Pal K and Palmer O (2000) A decision support system for business acquisitions. Decision Support System 27: 411-429.

Paradice DB (2002) Recognition of aesthetic dimension of information systems. Third Annual Global Information Technology Management World Conference, New York.

Pinson SD, Louca JA and Moraitis P (1997) A distributed decision support system for strategic planning. Decision Support Systems 20(1): 35-51.

Power DJ (2003) A brief history of decision support systems. DSS Resource.COM, available at http://DSSResources.COM/history/dsshistory.html

Raghavan SA (1991) JANUS: a paradigm for active decision support. Decision Support Systems 7: 379-395. 
Rao RH, Sridhar R and Narain S (1994) An active intelligent decision support system: an architecture and simulation. Decision Support Systems 12(1): 79-91.

Reich $Y$ and Kapeliuk A (2005) A framework for organising the space of decision problems with application to solving subjective, context-dependent problems. Decision Support Systems 41: 1-19.

Riecken D (1994) Introduction to special issue on intelligent agents. Communications of the ACM 37: 18-21.

Rodgers PA, Huxor AP and Caldwell NHM (1999) Design support using distributed Web-based Al tools. Research in Engineering Design 11: 31-44.

Saridakis KM and Dentsoras AJ (2006) Integration of fuzzy logic, genetic algorithms and neural networks in collaborative parametric design. Advanced Engineering Informatics 20: 379-399.

Saridakis K, Dimopoulos S, Karacaplidis N and Dentsoras A (2005) WebCo2Des: a Web-based system for collaborative conceptual design. In proceedings of $6^{\text {th }}$ International Conference on Computer-Aided Industrial Design and Conceptual Design, Delft, Netherlands.

Shaw MJ and Fox MS (1993) Distributed artificial intelligence for group decision support: integration of problem solving, co-ordination and learning. Decision Support Systems 9(4): 349-367.

Shi Z, Huang Y, He Q, Xu L, Liu S, Qin L, Jia Z, Huang H and Zhao L (2007) MSMiner - a developing platform for OLAP. Decision Support Systems 42: 2016-2028.

Shim JP, Warkentin M, Courtney JF, Power DJ, Sharda R and Carlsson C (2002) Past, present, and future of decision support technology. Decision Support Systems 33: 111-126.

Silva C, Roque L and Almeida A (2006) MAPP-a Web based decision support system for the mould industry. Decision Support Systems 42: 999-1014.

Simon HA (1960) The New Science of Management Decision. Harper Brothers. New York.

Simon HA (1977) The new Science of Management Decision. Prentice-Hall. Simon HA (1997) Administrative Behaviour. $4^{\text {th }}$ Edition. The Free Press, New York.

Szykman S, Fenves SJ, Keirouz W and Shooter SB (2001) A foundation for interoperability in next generation product development systems. Computer-Aided Design 33: 545-559.

Thapa D, Jung IS and Wang GN (2005) Agent based decision support system using reinforcement learning under emergency circumstances. Lecture Notes in Computer Science 3610: 888-892.

Thomas I and Nejmeh BA (1992) Definitions of tool integration for environments. IEEE Software 9(2): 29-35.

Thomsen E (1997) OLAP Solutions: Building Multi-dimensional Information Systems. Wiley, New York.

Tsai YC (1998) Model integration using SML. Decision Support Systems 22: 355-377.

Truck I and Akdag H (2006) Manipulation of qualitative degrees to handle uncertainty: formal models and applications. Knowledge and Information Systems: An International Journal 9(4): 385-411.

Turck FD, Decruyenaere J, Thysebaert P, Hoecke SV, Volckaert B, Danneels C, Colpaert K and Moor GD (2007) Design of a flexible platform for execution of medical decision support agents in the intensive care unit. Computers in Industry 37: 97-112. 
Vahidov R and Kersten GE (2004) Decision station: situating decision support systems. Decision Support Systems 38: 283-303.

Wang M, Wang H, Xu D, Wan KK and Vogal D (2004) A Web-service agent-based decision support system for securities exception management. Expert Systems with Applications 27: 439-450.

Whitfield RI, Duffy AHB and Wu Z (2005) An overview of VRS integration platform. Proceedings of the $15^{\text {th }}$ International Conference on Engineering Design. Melbourne, August 15-18, 2005.

Witten IH and Frank E (1999) Data Ming. Morgan Kaufmann. San Francisco, CA.

Zdrahal Z and Domingue J (1997) The World Wide Web design lab: an environment for distributed collaborative design. In proceedings of International Conference on Engineering Design (ICED), Tampere.

Zeleznikow J and Nolan JR (2001) Using soft computing to build real world intelligent decision support systems in uncertain domains. Decision Support Systems 31: 263285.

Zhang D, Zhou L and Nunamaker-Jr JF (2002) A knowledge management framework for the support of decision making in humanitarian assistance and disaster relief. Knowledge and Information Systems: An International Journal 4: 370-385.

Zhu Y, Pandit A and Mao W (2006) Framework to support the representation of semantic mappings for a hybrid integration strategy. Journal of Computing in Civil Engineering 20(4): 237-246.

\section{Author biographies}

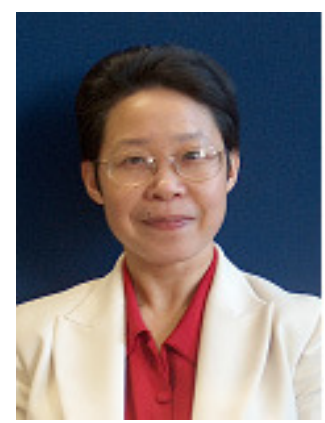

Dr Shaofeng Liu is a currently a Research Fellow in the CAD Centre at the University of Strathclyde. She received her PhD degree from Loughborough University in 2004 specialising in information and knowledge models for global manufacturing coordination decisions. Her research interests and strengths include information and knowledge management, decision making and decision support, software tool support for engineering management, and systems integration. She has been involved in a number of research projects concerned with information and knowledge systems, decision support systems and integration for design manufacture and engineering management. Currently, she is working on NECTISE project and focusing on integration for decision support.

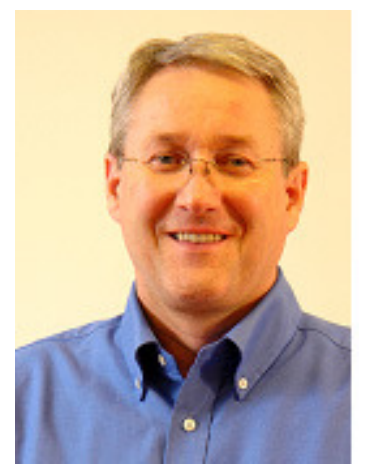

Professor Alex Duffy is the Director of the CAD Centre within the Department of Design Manufacture and Engineering Management at the University of Strathclyde. He lectures in design management, product development, knowledge intensive CAD, advanced computational techniques, and databases. His main research interests have been the application of knowledge based techniques in design, product and domain knowledge modelling, machine learning 
techniques and design re-use, performance measurement, and design co-ordination. He has been the Co-ordinator and Topic Leader of a number of big EU and UK funded projects. He has published more than 190 papers. He is the Editor-in-Chief of the Journal of Engineering Design, and on the editorial board of a number of international journals in the area of design, design computing and Artificial Intelligence in design. He is currently the vice-president, and prior to this the President, of the Design Society, an international body encompassing all aspects and disciplines of design.

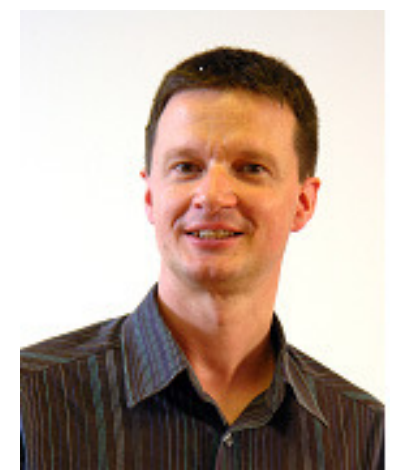

Dr Robert lan Whitfield is a lecturer in the Department of Design Manufacture and Engineering Management at the University of Strathclyde. He has been involved with both the proposal writing, management and conducting of research within a number of large FP5 and FP6 integrated projects (VRShips, VIRTUE, SAFEDOR) within the shipbuilding industry - typically with between 30 and 50 partners, and has garnered significant knowledge in how to achieve collaboration between a large number of partners for successful project completion. These projects have each focussed upon the development of collaborative tools and techniques for the integration of distributed design expertise across Europe. He is currently involved within a joint BAE Systems EPSRC research project - NECTISE that is defining techniques for supporting collaborative decision making within a network-enabled organisation. His research background subsequently covers issues relating to: co-ordination, collaboration, integration, resource management, process modelling and optimisation and modular design.

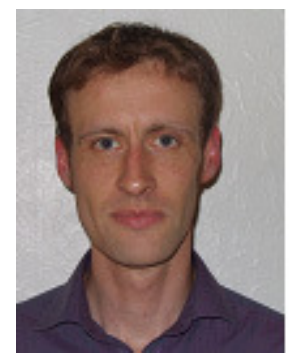

lain Boyle is a Research Fellow in the Department of Design, Manufacture and Engineering Management at the University of Strathclyde, Glasgow, UK. His PhD in Manufacturing Engineering, awarded in 2006, focused upon supporting flexible decisionmaking within the design process through understanding the links between behavioural, structural, and functional knowledge. This work has been published at both journal and conference level. Currently, he is extending his research to provide agile decision support within organizational decision-making environments. 